\title{
Antioxidant and anti-Helicobacter pylori activities of Hericium erinaceus mycelium and culture filtrate
}

\author{
Luong Thi My Ngan*(i), Nguyen Thien Vi, Doan Thi Mong Tham, Le Thi Thanh Loan, Pham Thanh Ho, \\ Tran Trung Hieu*
}

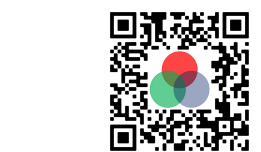

Use your smartphone to scan this QR code and download this article

Faculty of Biology and Biotechnology, VNUHCM University of Science, Ho Chi Minh City, Vietnam

\section{Correspondence}

Luong Thi My Ngan, Faculty of Biology and Biotechnology, VNUHCM University of Science, Ho Chi Minh City, Vietnam

Email: Itmngan@hcmus.edu.vn

Correspondence

Tran Trung Hieu, Faculty of Biology and Biotechnology, VNUHCM University of Science, Ho Chi Minh City, Vietnam

Email: hieutt@hcmus.edu.vn

History

- Received: Dec 23, 2020

- Accepted: Mar 26, 2021

- Published: Mar 31, 2021

DOI : 10.15419/bmrat.v8i3.665

\section{Check for updates}

Copyright

(C) Biomedpress. This is an openaccess article distributed under the terms of the Creative Commons Attribution 4.0 International license.

\begin{abstract}
Introduction: Hericium erinaceus is known as a medicinal edible mushroom owing to its antimicrobial, antioxidant, anti-tumor and immunomodulatory effects. Helicobacter pylori infection is one of the major health concerns worldwide due to its high rate in global populations, frequent recurrence, and rapid emergence of drug-resistant strains. The present study aims to investigate antioxidant, anti-H. pylori, and urease inhibitory activities of solvent fractions from $\mathrm{H}$. erinaceus mycelium and culture filtrate. Methods: H. erinaceus mycelium was purely cultured in a liquid medium. A polysaccharide fraction was obtained from the culture filtrate by precipitation with ethanol. The mycelium and culture filtrate were extracted by liquid extraction to obtain solvent-soluble fractions. The antibacterial effects of these fractions were determined using paper disc diffusion and broth microdilution assays. Urease inhibition was determined using the salicylate-hypochlorite method. The antioxidant activity of $H$. erinaceus was evaluated via 2,2,1-diphenyl-1-picrylhydrazyl (DPPH) radical scavenging activity. Results: The ethyl-acetate (EtOAc) fractions derived from $\mathrm{H}$. erinaceus culture filtrate (fEtOAc Fr.) and mycelium (mEtOAc Fr.) showed the strongest anti-H. pylori activity with MIC (MBC) of $1.25-1.5(5.0-7.5) \mathrm{mg} / \mathrm{mL}$ and potential urease inhibitory activity with $\mathrm{IC}_{50}$ of $0.34-0.35 \mathrm{mg} / \mathrm{mL}$. In addition, fEtOAc Fr. exhibited the greatest antioxidant activity $\left(\mathrm{IC}_{50}, 11.83\right.$ $\mathrm{mg} / \mathrm{mL}$ ), which was slightly stronger than that of $\mathrm{mEtOAC} \mathrm{Fr.}\left(\mathrm{I}_{50}, 14.75 \mathrm{mg} / \mathrm{mL}\right)$. Moreover, our study also found that the water fractions from the culture filtrate (fWater Fr.) and the mycelium (mWater Fr.) displayed considerable inhibitory activities against bacterial urease $\left(\mathrm{IC}_{50}, 1.26-1.40\right.$ $\mathrm{mg} / \mathrm{mL}$ ), although they showed low or no anti-H. pylori and antioxidant activities. Conclusion: The present study revealed that the EtOAC fractions derived from the $H$. erinaceus mycelium and culture filtrate potentially have anti-H. pylori, anti-urease and antioxidant activities. These results suggest that $H$. erinaceus mycelium and culture filtrate could be utilized to develop functional foods and nutraceuticals to prevent $H$. pylori infection. More research is needed to prove the safety of the $H$. erinaceus mycelium and culture filtrate fractions and their in vivo efficacy in the treatment of $H$. pylori infection.
\end{abstract}

Key words: Antibacterial activity, Antioxidant, Culture filtrate, Helicobacter pylori, Hericium erinaceus, Mycelium

\section{INTRODUCTION}

Hericium erinaceus (Bull.) Pers., known as lion's mane mushroom, grows on old or dead hardwood trees in America and Asia and is widely consumed due to its nutritional qualities and health benefits. The mushroom has long been used as a folk medicine to treat various human diseases in several East Asian countries ${ }^{1}$. It provides numerous essential nutrients and constituents such as polysaccharides, proteins, lectins, phenols, isoindolinones, hericenones, erinacine terpenoids, and sterols, several of which possess various pharmacological properties $^{2-4}$. H. erinaceus extracts showed to be effective in stimulating the synthesis of immune system components ${ }^{2,5}$, which contribute to inhibiting tumor cell growth ${ }^{6}$. The mushroom displayed clinical potential in relieving inflammatory bowel disease by regulating gut microbiota and immune system ${ }^{7}$. Polysaccharide fraction derived from $H$. erinaceus has also induced immunomodulating and anti-tumor effects $^{6}$, anti-gastritis activity, and significantly enhanced skin antioxidant enzymes that help retard skin aging ${ }^{8}$. In addition, the fruiting body of $H$. erinaceus has been traditionally used to ameliorate gastrointestinal disorders and treat symptoms related to gastric ulcers ${ }^{7,9,10}$. H. erinaceus extracts were found to have antimicrobial activities against both Grampositive and -negative pathogenic bacteria ${ }^{11,12}$, and both antibiotic-resistant and -susceptible Helicobacter pylori ${ }^{13}$, a human gastrointestinal pathogen involved in gastritis, duodenal ulcers, and gastric can- 
$\operatorname{cer}^{14,15}$. Ethanol extracts from $H$. erinaceus fruiting bodies were reported to exhibit growth inhibitory effects on $H$. pylori by in vitro and/or in vivo studies $9,10,13$.

Besides, extracts derived from the mycelium culture of $H$. erinaceus were reported to be active against pathogenic bacteria ${ }^{11}$, hepatocarcinoma cells ${ }^{16}$, stimulate nerve growth factor synthesis ${ }^{17}$, and prevent oxidative stress in human gastric mucosa epithelium cell ${ }^{18}$. The pure culture of $H$. erinaceus mycelium has been recently being studied and developed, especially for the production of nutraceuticals and pharmaceuticals. However, there is less information focusing on the antibacterial activity of $H$. erinaceus mycelium against $H$. pylori. Therefore, the present study was aimed to assess the possible antioxidant effect and growth-inhibitory, bactericidal, and urease inhibitory activities of the polysaccharide and solvent fractions extracted from mycelium and culture filtrate of $H$. erinaceus toward H. pylori.

\section{MATERIALS - METHODS}

\section{Reagents}

Brucella broth (BB), brain heart infusion broth (BHIB), and bacto-agar were purchased from Becton Dickinson, Inc. (Franklin Lakes, NJ). Newborn bovine serum (NBS) was purchased from Hyclone (Longan, UT). Tryptone and yeast extract were provided by Merck (Kenilworth, NJ) and glucose was provided by HiMedia (Kennett Square, PA). Amoxicillin ( $\geq 98 \%$ ) was provided by Santa Cruz Biotechnology Inc. (Dallas, TX). Solvents, hexane 96\%, ethyl acetate (EtOAc) 99.8\%, absolute ethanol (EtOH), and methanol (MeOH) 99.9\% were purchased from Scharlau (Barcelona, Spain). All other chemicals and reagents used in this study were of analytical grade quality and available commercially.

\section{Broth culture of $H$. erinaceus and solvent ex- traction of the mycelium and culture filtrate}

Hericium erinaceus mycelium was provided and identified by Dr. Pham Thanh Ho, Laboratory of Biotransformation, Faculty of Biology and Biotechnology, VNUHCM University of Science, Ho Chi Minh City, Vietnam. H. erinaceus mycelium could produce fruiting bodies in the laboratory conditions. The mycelium and fruiting bodies were cultured and stored at $4{ }^{\circ} \mathrm{C}$.

Four pieces of $H$. erinaceus mycelium $\left(1 \mathrm{~cm}^{2} /\right.$ each $)$ from 8 day-old culture on agar medium were inoculated in $500 \mathrm{~mL}$ bottles containing $200 \mathrm{~mL}$ liquid medium with the following composition: $20 \%$ potato extract, $2 \%$ glucose, $0.2 \%$ yeast extract, and $0.2 \%$ tryptone. The broth cultures were incubated at $25 \pm 2{ }^{\circ} \mathrm{C}$ and shaken at $150 \mathrm{rpm}$ for 7 days ${ }^{11}$. After that, the culture broths were filtered to obtain the mushroom mycelium and culture filtrate for solvent extraction, as shown in Figure 1.

The dry mycelium was disrupted by liquid nitrogen in 30 minutes. The mycelium was then finely grounded and extracted with $200 \mathrm{~mL}$ hexane for 1 day (3 times) and further extracted sequentially with $200 \mathrm{~mL}$ EtOAc for 1 day ( 3 times) and $500 \mathrm{~mL}$ hot water for 2 hours. The extracts were filtered, and a rotary evaporator was used to remove the solvents to obtain a hexanesoluble fraction (mHexane Fr.), EtOAc-soluble fraction (mEtOAc Fr.), and water-soluble fraction ( $\mathrm{mWa}$ ter Fr.) (Figure 1).

The culture filtrate was precipitated with 4 times volume of cold absolute EtOH $\left(1^{\circ} \mathrm{C}\right)$ overnight and then centrifuged to obtain the crude polysaccharide fraction (precipitant). The polysaccharide fraction (PS Fr.) was dissolved in sodium phosphate buffer buffer (30 mM, pH 7) to a $200 \mathrm{mg} / \mathrm{mL}$ stock concentration and stored at $-20{ }^{\circ} \mathrm{C}$ until further use. After the precipitation, the filtrate was then fractionated sequentially three times with an equal volume of hexane for 2 hours, and then three times with an equal volume of EtOAc for 2 hours using the liquid-liquid method. The solvent-soluble fractions were condensed to dryness by a rotary evaporator at $42^{\circ} \mathrm{C}$ to gain the hexane fraction (fHexane Fr.), EtOAc fraction (fEtOAc Fr.), and water fraction (fWater Fr.) (Figure 1).

\section{H. pylori strain and culture condition}

The H. pylori strain (ATCC 43504) was provided by the Oxford University Clinical Research Unit in Vietnam (OUCRU-VN) and identified by matrix-assisted laser desorption/ionization time-of-flight mass spectrometry (MALDI-TOF MS). The bacterial strain was stored in BHIB medium supplemented with $25 \%$ glycerol and placed in a nitrogen liquid container until use.

The H. pylori strain was cultured on Brucella agar supplemented with $10 \%$ newborn bovine serum, and then incubated at $37^{\circ} \mathrm{C}$ in 3 days under microaerophilic condition created by a $2.5 \mathrm{~L}$ Oxoid anaerojar and Oxoid Campygen sachet (Thermo Fisher Scientific, Waltham, MA, USA). The bacterial suspensions used for bioassay were suspended in Brucella broth supplemented with 5\% NBS using a 72h subculture of $H$. pylori on Brucella agar. Bacterial density was determined using McFarland turbidity standards. 


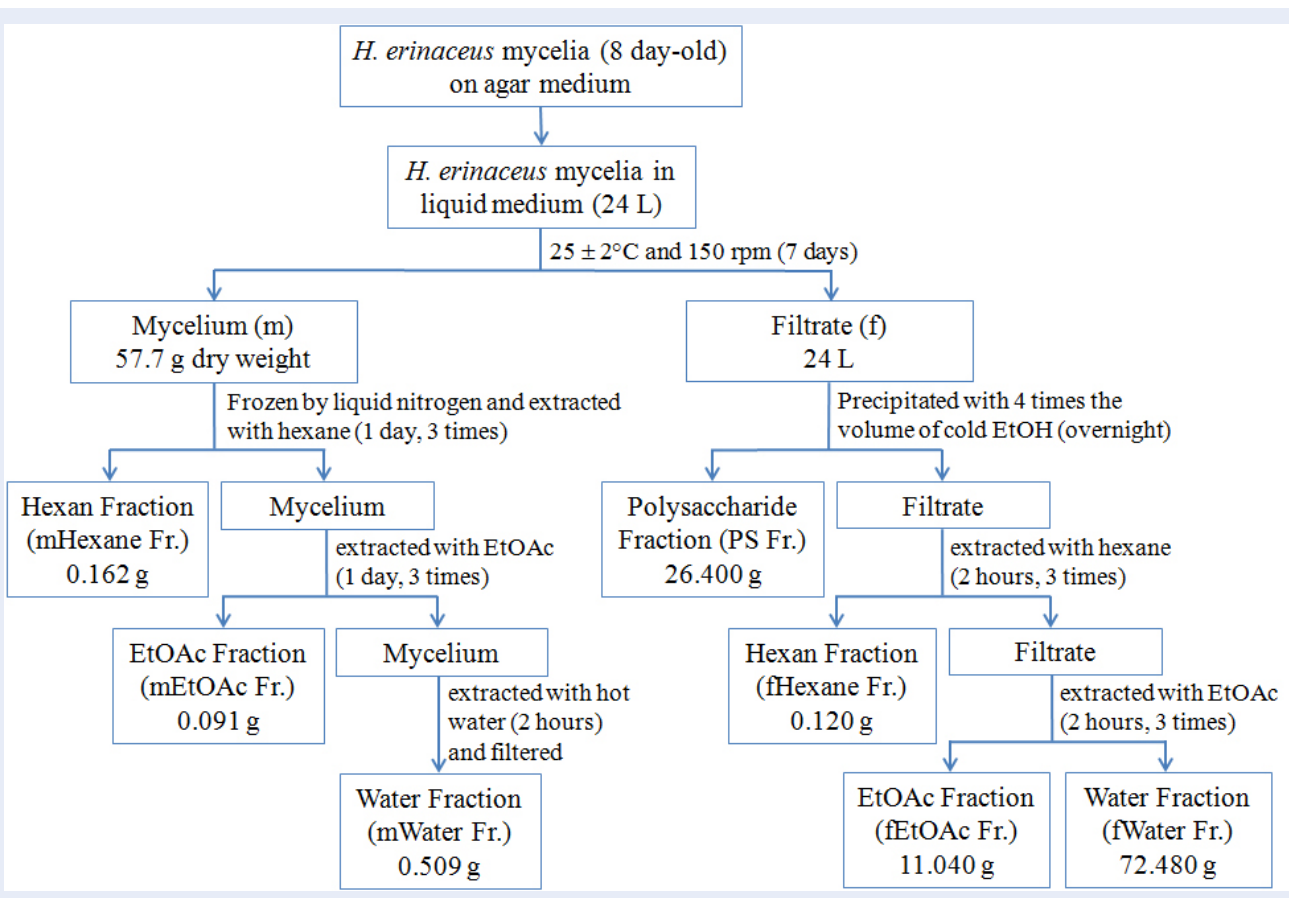

Figure 1: Broth culture of $\boldsymbol{H}$. erinaceus and solvent extraction of the mycelium and culture filtrate.

\section{Antibacterial assay}

\section{Paper disc diffusion assay}

The antibacterial activity of the fractions extracted from the $H$. erinaceus mycelium and culture filtrate was evaluated using paper-disc diffusion method, as previously described ${ }^{19}$. In brief, $100 \mu \mathrm{L}$ of $H$. $p y$ lori suspensions $\left(10^{8} \mathrm{CFU} / \mathrm{mL}\right)$ were evenly spread on Brucella agar medium in petri plates $(\varnothing 90 \mathrm{~mm}$, SPL Life Sciences, Korea). Sterile paper discs ( $1 \mathrm{~mm}$ thickness, $6 \mathrm{~mm}$ diameter) from Whatman/ GE Healthcare (UK) impregnated with $20 \mu \mathrm{L}$ of respective test material $(500 \mu \mathrm{g} / \mu \mathrm{L})$ in DMSO were placed on the plate surface. DMSO (20 $\mu \mathrm{L} /$ disc $)$ and amoxicillin (10 $\mu \mathrm{g} /$ disc) were similarly prepared and used as negative and positive controls, respectively. The test and control plates were incubated at $37{ }^{\circ} \mathrm{C}$ under the microaerophilic condition for 3 days. After incubation, the inhibition zone was measured. The assay was performed in duplicate three times. The inhibitory responses were classified as follows: very strong response with inhibition zone diameter $>28 \mathrm{~mm}$, strong response with inhibition zone diameter of $>17-28$ $\mathrm{mm}$, moderate response with inhibition zone diameter of $>13-17 \mathrm{~mm}$, weak response with inhibition zone diameter of $8-13 \mathrm{~mm}$, and little or no response with inhibition zone diameter $<8 \mathrm{~mm}$.

\section{MIC and MBC assay}

The minimal inhibitory concentration (MICs) and minimal bactericidal concentration (MBCs) of the fractions extracted from $H$. erinaceus mycelium and culture filtrate towards $H$. pylori were evaluated using broth microdilution method, as reported previously ${ }^{19}$. Briefly, the fractions in DMSO $(10 \mu \mathrm{L}$ each $)$ at various final concentrations $(0-10 \mathrm{mg} / \mathrm{mL})$ were added to each well of sterile 96-well plates, which contained $40 \mu \mathrm{L}$ of Brucella broth medium supplemented with $5 \%$ NBS. Subsequently, $50 \mu \mathrm{L}$ bacterial suspension $\left(5.10^{6} \mathrm{CFU} / \mathrm{mL}\right)$ from cultures on Brucella agar was seeded into each well. DMSO and amoxicillin served respectively as negative and positive controls and were similarly prepared. The plates were incubated at $37^{\circ} \mathrm{C}$ in a gas jar under microaerophilic conditions and shaken at $50 \mathrm{rpm}$ for 48 hours. MIC values were determined as the lowest concentrations that showed bacterial growth inhibition using resazurin as an indicator. MBC values of the test fractions were performed following the MIC assays in 24-well plates with Brucella agar medium as previously described ${ }^{20}$. MIC and MBC values of each test sample were results from at least three independent experiments performed in triplicate $(n \geq 9)$. 


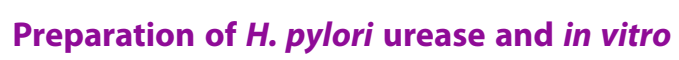
inhibition of urease activity

H. pylori urease crude extract was prepared as reported previously ${ }^{21}$ with slight modification. Briefly, an amount of $500 \mathrm{mg}$ of $H$. pylori cell mass from 72 $\mathrm{h}$ cultures on NBS-supplemented Brucella agar was spread as thinly as possible on the wall of a polypropylene tube and stored in a nitrogen liquid container for 15 minutes. The cell mass was then thawed at room temperature and added with $5 \mathrm{~mL}$ of $20 \mathrm{mM}$ sodium phosphate buffer ( $\mathrm{pH} 7.3)$ containing EDTA (1 mM). Finally, the mixture was centrifuged at $12,000 \times \mathrm{g}, 4^{\circ} \mathrm{C}$ for 30 minutes, and the supernatant was filtered using a $0.22 \mu \mathrm{m}$ Millex GV Millipore filter. The protein content was determined using Bradford protein assay. Bovine serum albumin (BSA) was used as a protein standard.

H. pylori urease inhibitory activity of the fractions extracted from $H$. erinaceus mycelium and culture filtrate was assayed in 96-well plates using the salicylatehypochlorite method with minor modification ${ }^{22}$. In brief, $50 \mu \mathrm{L}$ of $0.25 \mu \mathrm{g} \mathrm{H}$. pylori urease crude preparation (0.04 urease units) in EDTA-sodium phosphate buffer ( $\mathrm{pH}$ 7.3) was added to each well containing 50 $\mu \mathrm{L}$ of the test fraction at various concentrations. The plates were preincubated at $37^{\circ} \mathrm{C}$ and shaken at 50 rpm for 90 minutes. An amount of $50 \mu \mathrm{L}$ of $5 \mathrm{mM}$ urea in phosphate buffer saline (PBS) was added into each well. After 30 minutes of incubation, a stop solution consisting of $35 \mu \mathrm{L}$ of solution A (146\% Na salicylate $+0.1 \%$ sodium nitroprusside) and $65 \mu \mathrm{L}$ of solution $\mathrm{B}(1.78 \% \mathrm{NaOH}+11.57 \% \mathrm{Na}$ citrate + $0.54 \%$ active $\mathrm{NaOCl}$ ) were supplemented in sequence to each well. The plates were incubated for 30 minutes at $37^{\circ} \mathrm{C}$ for color development. The ammonia production released from the hydrolysis of urea by urease activity was quantified by measuring absorbance on the microplate reader at $625 \mathrm{~nm}$ using ammonium chloride as a standard. Thiourea as a standard reference was similarly prepared. Inhibition rate (I\%) was calculated by the following formula: I (\%) $=\left[1-\left(\mathrm{OD}_{625}\right.\right.$ test sample $-\mathrm{OD}_{625}$ correspond ing background $) /\left(\mathrm{OD}_{625}\right.$ control $-\mathrm{OD}_{625}$ blank $\left.)\right]$ $\times 100$. Urease inhibition activity of the fractions was displayed as $50 \%$ inhibitory concentration $\left(\mathrm{IC}_{50}\right)$, which was defined as the concentration of the fractions required to decrease urease activity to $50 \%$ of the control value. The assay was performed in duplicate three times.

\section{DPPH free radical scavenging assay}

The antioxidant activities of the fractions extracted from $H$. erinaceus mycelium and culture filtrate were evaluated via 2,2,1-diphenyl-1-picrylhydrazyl (DPPH) free radical scavenging activity with slight modification ${ }^{11}$. The experiment was performed in 96-well plates. The fraction solutions in $\mathrm{MeOH}$ at various concentrations from $0-50 \mathrm{mg} / \mathrm{mL}$ were placed in the wells, and $150 \mu \mathrm{L}$ of $380 \mu \mathrm{M} \mathrm{DPPH}$ in $\mathrm{MeOH}$ was then added to each well. Blank and background wells, which contained $\mathrm{MeOH}$ and the fractions, respectively, without DPPH, were also prepared. The plates were placed in the dark and incubated at $37^{\circ} \mathrm{C}$ with rotation at $75 \mathrm{rpm}$ for $30 \mathrm{~min}$ utes. Subsequently, the absorbance measurements were determined at $515 \mathrm{~nm}$ on a Microlisa Plus microplate reader (Micro Lab Instruments, India). Acid ascorbic $(0-0.5 \mathrm{mg} / \mathrm{mL})$ served as a positive control and was similarity prepared. The percent radical scavenging activity was calculated as follows: percent scavenging effect $(\%)=\left[1-\left(\mathrm{OD}_{\text {treatment }}-\right.\right.$ $\left.\left.\mathrm{OD}_{\text {background }}\right) /\left(\mathrm{OD}_{\text {control }}-\mathrm{OD}_{\text {blank }}\right)\right] \times 100$, where $\mathrm{OD}_{\text {control }}, \mathrm{OD}_{\text {blank }}, \mathrm{OD}_{\text {treatment, }}$ and $\mathrm{OD}_{\text {background }}$ are absorbance values of the controls, blanks, fraction treatments, and background wells, respectively.

\section{Data analysis}

All bioassays were repeated three to five times in triplicate. The inhibition zones of the test fractions were presented in mean values $( \pm \mathrm{SD})$. DPPH $\mathrm{IC}_{50}$ and urease $\mathrm{IC}_{50}$ (half maximal inhibitory concentration) values were calculated using GraphPad Prism 5 software program (GraphPad Software, Inc., La Jolla, CA, USA). The $\mathrm{IC}_{50}$ values of the treatments would be declared significantly different if their $95 \%$ confidence intervals did not overlap.

\section{RESULTS}

\section{Solvent extraction of the mycelium and cul- ture filtrate of $\boldsymbol{H}$. erinaceus}

After 7 days of incubations, the culture broths of $H$. erinaceus were filtered to obtain $57.7 \mathrm{~g}$ dry weight of the mycelium and $24 \mathrm{~L}$ of its culture filtrate. Solventsoluble fractions obtained from the dry mycelium and culture filtrate are presented in Figure 1.

From the dry mycelium $(57.7 \mathrm{~g})$, the three fractions of mHexane Fr., mEtOAc Fr. and mWater Fr. were obtained, and weighed as $0.162,0.091$ and $0.509 \mathrm{~g}$, respectively (Figure 1).

From $24 \mathrm{~L}$ of the culture filtrate, the four fractions of PS Fr. (26.4 g), fHexane Fr. $(0.12 \mathrm{~g})$, fEtOAc Fr. (11.04 g) and fWater Fr. (72.48 g) were obtained (Figure 1). The yields of the Hexane and EtOAc fractions were lower than those of the PS and Water fractions. This implied that there were very few non-polar components in the mycelium and culture filtrate. 


\section{Antibacterial assays}

The results from the paper disc diffusion method are summarized in Table 1 and Figure 2. The results revealed that the EtOAc fractions from both the mycelium (mEtOAc Fr.) and filtrate (fEtOAc Fr.) had strong anti-H. pylori activity with inhibition zones of 18 - 19 mm, while mHexane Fr. and PS Fr. showed weak activity with 12 and $9 \mathrm{~mm}$ inhibition zones, respectively. However, mWater Fr., fHexane Fr. and fWater Fr. showed no inhibitory activity (Table 1). All fractions displayed weaker inhibitory activity than the positive control amoxicillin (inhibition zone of $37.5 \mathrm{~mm}$ ).

The MIC and MBC results also yielded similar results (Table 1). The fractions mEtOAC Fr. and fEtOAC Fr. showed strong anti- $H$. pylori activity with MIC (MBC) values of 1.5 (7.5) and $1.25(5.0) \mathrm{mg} / \mathrm{mL}$, respectively. However, mHexane Fr. and PS Fr. displayed weak anti-H. pylori activity with MIC (MBC) values of $7.5(\geq 10) \mathrm{mg} / \mathrm{mL}$, while fHexane Fr., mWater Fr. and fWater Fr. showed no inhibitory activity (MIC $\geq 10 \mathrm{mg} / \mathrm{mL}$ ). The $H$. pylori ATCC 43504 strain was susceptible to the positive control amoxicillin with MIC (MBC) values of $0.032(0.063) \mu \mathrm{g} / \mathrm{mL}$.

\section{Urease inhibition}

Based on urease $\mathrm{IC}_{50}$ data presented in Table 2, mEtOAc Fr. and fEtOAc Fr. displayed strong urease inhibitory activity with $\mathrm{IC}_{50}$ values of 0.34 and $0.35 \mathrm{mg} / \mathrm{mL}$, respectively, with a non-significant difference $(\mathrm{p}>0.05)$. This was followed by the inhibitory activity of mWater Fr. and fWater Fr. ( $\mathrm{IC}_{50}$ values of 1.26 and $1.40 \mathrm{mg} / \mathrm{mL}$, respectively). Besides, both mEtOAc Fr. and fEtOAc Fr. caused a steep doseresponse curve of the percentage of urease inhibitory activity and produced a complete inhibition against the urease at $2.5 \mathrm{mg} / \mathrm{mL}$, whereas mWater Fr. and fWater Fr. showed a complete inhibition against the urease at 3 and $>5 \mathrm{mg} / \mathrm{mL}$, respectively (Figure 3 ). Moreover, PS Fr., mHexane Fr. and fHexane Fr. gave very weak or no inhibitory activity towards the enzyme. All the fractions exhibited lower urease inhibitory activity than the positive control thiourea ( $\mathrm{IC}_{50}, 0.055 \mathrm{mg} / \mathrm{mL}$ ) (Table 2).

\section{DPPH free radical scavenging}

Based on DPPH $\mathrm{IC}_{50}$ values presented in Table 3, fEtOAc Fr. displayed the greatest antioxidant activity in the DPPH assay $\left(\mathrm{IC}_{50}\right.$ of $11.83 \mathrm{mg} / \mathrm{mL}$ ), followed by mEtOAc Fr. ( $\mathrm{IC}_{50}$ of $14.75 \mathrm{mg} / \mathrm{mL}$ ), with a significant difference $(p<0.01)$. Moreover, PS Fr., mWater Fr. and fWater Fr. showed weak or very weak antioxidant activity $\left(\mathrm{IC}_{50}, 28.66-34.51 \mathrm{mg} / \mathrm{mL}\right)$. In addition, $\mathrm{fE}$ tOAc Fr. caused a steep dose-response curve of percentage of DPPH radical scavenging activity and complete inhibition at $40 \mathrm{mg} / \mathrm{mL}$ (Figure 4). Fractions mHexane Fr. and fHexane Fr. had no radical scavenging activity. Overall, all of these fractions showed significantly weaker DPPH radical scavenging activity than the positive control acid ascorbic ( $\mathrm{IC}_{50}$ of 0.057 $\mathrm{mg} / \mathrm{mL}$ ) (Table 3).

\section{DISCUSSION}

Oxidative stress and chronic inflammation have been known to play critical roles in the pathogenesis of gastritis and gastric ulcers caused by various stimuli, including H. pylori ${ }^{23}$. Various physiological effects of $H$. erinaceus (lion's mane mushroom) have been presented, including anti-aging, anti-cancer, anti-gastritis, and anti-metabolic disease properties $^{1,6-8,24}$. The mushroom's bioactive components, such as erinacines and hericenones, were extracted or concentrated as nutraceuticals because they have been revealed to act as the active principles for nerve growth factor synthesis and in neuroprotective function ${ }^{25-27}$. H. erinaceus is quite rare in the wild. However, by artificial cultivation techniques, its fruiting body and mycelium are nowadays being produced as raw materials for culinary and medicinal use. H. erinaceus has become attractive as a disease-preventing functional food and as a source of medicines. $H$. erinaceus aqueous and $50 \%$ EtOH extracts were demonstrated to possess immune-stimulatory activity to protect infected mice against Salmonella Typhimurium ${ }^{12}$. Methanolic extract from a pure culture of $H$. erinaceus mycelium was reported to produce weak inhibitory activity against Bacillus cereus, B. subtilis, Enterococcus faecalis, Salmonella sp., Shigella sp. and Plesiomonas shigelloides ${ }^{11}$. However, EtOH extract from fruiting body of $H$. erinaceus has been shown to exhibit similar growth inhibitory effects on several strains of $H$. $p y$ lori $i^{9,10,13}$. Petroleum ether, chloroform, and EtOAc fractions from the fruiting body extract were reported to exhibit a stronger growth inhibitory activity than the crude extract against $H$. pylori ${ }^{9,13}$. In our present study, mEtOAc Fr. and fEtOAc Fr. from mycelium and culture filtrate of $H$. erinaceus displayed stronger anti-H. pylori activity than the polysaccharide, hexane and water fractions.

Findings on the mechanism of $H$. erinaceus action against $H$. pylori have indicated that the mushroom extracts helped prevent oxidative stress in human gastric mucosa epithelium cell ${ }^{18}$ and inhibit the adhesion ability of $H$. pylori to the host cell, thereby contributing to reduction of the bacterial infection in 
Table 1: Antibacterial activities of $\boldsymbol{H}$. erinaceus mycelium and culture filtrate fractions against $\boldsymbol{H}$. pylori ATCC 43504

\begin{tabular}{lccc}
$\begin{array}{l}\text { Test material } \\
(\mathbf{1 0 ~} \mathbf{~ m} \text { /disc })\end{array}$ & $\begin{array}{c}\text { Inhibition zone } \\
(\mathbf{m m})\end{array}$ & $\begin{array}{c}\text { MIC } \\
(\mathbf{m g} / \mathbf{m L})\end{array}$ & $\begin{array}{c}\text { MBC } \\
(\mathbf{m g} / \mathbf{m L})\end{array}$ \\
fEtOAc Fr. & $18.8 \pm 0.75^{b}$ & 1.25 & 5 \\
mEtOAc Fr. & $17.7 \pm 1.03^{b}$ & 1.5 & 7.5 \\
mHexane Fr. & $12.3 \pm 0.82^{c}$ & 7.5 & 10 \\
PS Fr. & $9.3 \pm 0.52^{d}$ & 7.5 & $>10$ \\
fHexane Fr. & - & 10 & $>10$ \\
mWater Fr. & - & $>10$ & \\
fWater Fr. & - & $>10$ & 0.063 \\
Amoxicillin & $37.5 \pm 2.51^{a}$ & 0.032 & \\
\hline
\end{tabular}

${ }^{*}$ Means $\pm \mathrm{SD} .{ }^{a, b, c, d}$ Mean values within a column followed by the same letter are not significantly different $(\mathrm{P}=0.05$; Bonferroni method $)$ ** positive control (10 $\mu \mathrm{g} / \mathrm{disc}), \mathrm{MIC}$ and $\mathrm{MBC}(\mu \mathrm{g} / \mathrm{mL})$

No activity
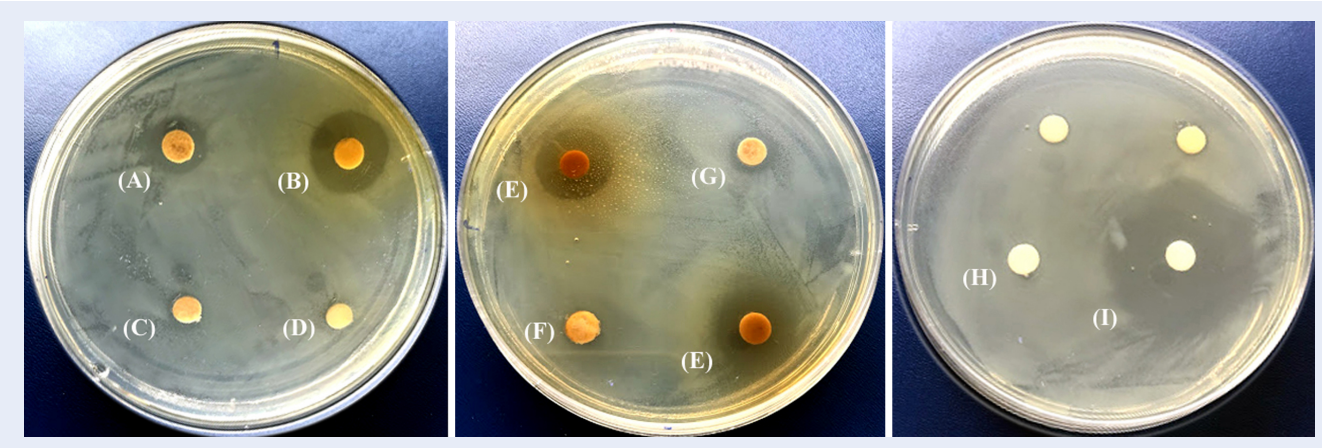

Figure 2: Antibacterial of $\boldsymbol{H}$. erinaceus mycelium and culture filtrate fractions toward $\boldsymbol{H}$. pylori ATCC 43504 using paper disc diffusion assay. Inhibition zones of mHexane Fr. (A), mEtOAc Fr. (B), mWater Fr. (C), fHexane Fr. (D), fEtOAc Fr (E), fWater Fr. (F), PS Fr. (G), negative control DMSO (H), and positive control amoxicillin (I).

Table 2: $\boldsymbol{H}$. pylori urease inhibitory activity of $\boldsymbol{H}$. erinaceus mycelium and culture filtrate fractions

\begin{tabular}{lcc}
\hline Test material & Slope \pm SE & Urease IC $_{50}, \mathbf{m g} / \mathbf{m L}(\mathbf{9 5} \% \mathbf{C L})$ \\
mEtOAc Fr. & $0.81 \pm 0.056$ & $0.34(0.30-0.39)$ \\
fEtOAc Fr. & $1.25 \pm 0.118$ & $0.35(0.31-0.40)$ \\
mWater Fr. & $1.56 \pm 0.269$ & $1.26(1.02-1.55)$ \\
fWater Fr. & $0.47 \pm 0.077$ & $1.40(1.12-1.74)$ \\
PS Fr. & $1.59 \pm 0.265$ & $29.67(26.12-33.70)$ \\
mHexane Fr. & $2.13 \pm 0.173$ & $30.26(28.53-32.10)$ \\
fHexane Fr. & & $\mathrm{ND}$ \\
Thiourea & $1.65 \pm 0.215$ & $0.055(0.049-0.062)$ \\
\hline
\end{tabular}

ND: not determined

CI: confidence interval 


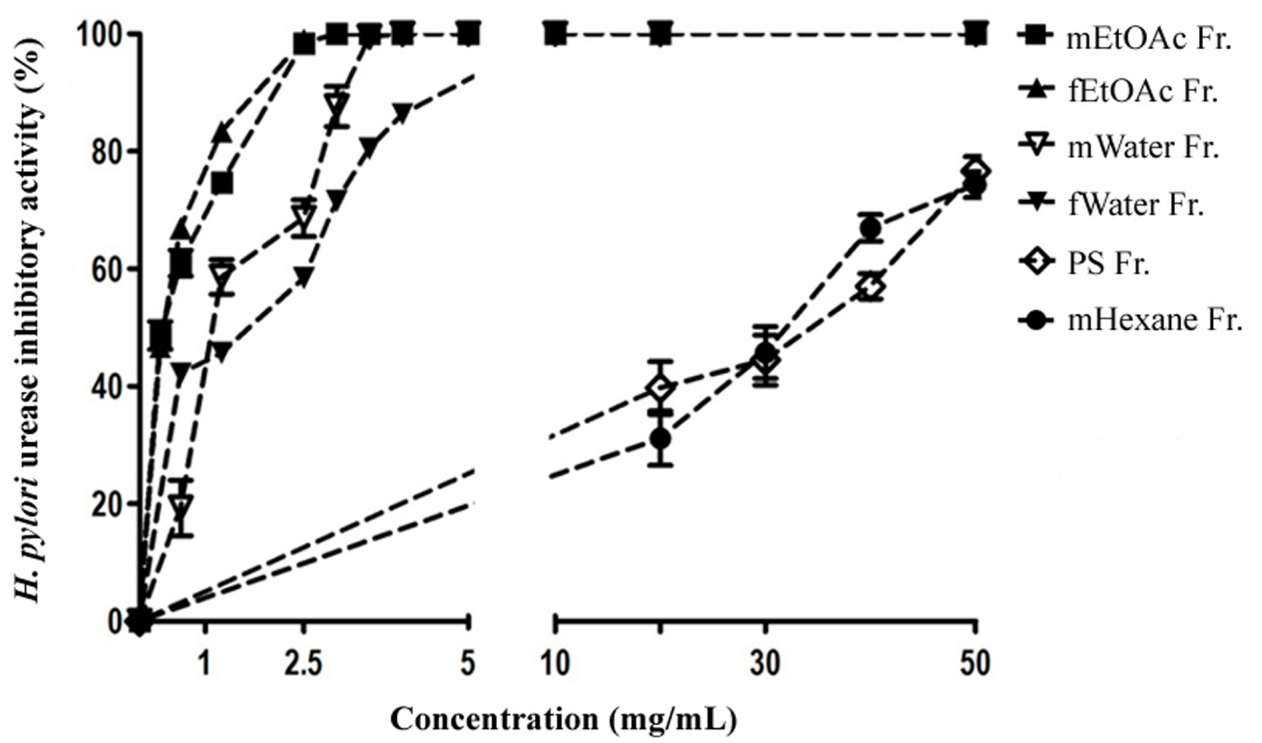

Figure 3: H. pylori urease inhibitory activity of $H$. erinaceus mycelium and culture filtrate fractions.

Table 3: DPPH free radical scavenging activity of $H$. erinaceus mycelium and culture filtrate fractions

\begin{tabular}{lcc}
\hline Test material & Slope \pm SE & DPPH IC $50, \mathbf{m g} / \mathbf{m L}(\mathbf{9 5} \% \mathbf{C L})$ \\
\hline fEtOAc Fr. & $2.322 \pm 0.339$ & $11.83(10.48-13.36)$ \\
mEtOAc Fr. & $2.972 \pm 0.421$ & $14.75(13.52-16.09)$ \\
PS Fr. & $3.217 \pm 0.256$ & $26.04(24.77-27.38)$ \\
mWater Fr. & $3.03 \pm 0.365$ & $28.66(26.6-30.87)$ \\
fWater Fr. & $1.879 \pm 0.211$ & $34.51(31.90-37.34)$ \\
mHexane Fr. & & $\mathrm{ND}$ \\
fHexane Fr. & & $\mathrm{ND}$ \\
Acid ascorbic & $2.712 \pm 0.567$ & $0.057(0.048-0.065)$ \\
\hline
\end{tabular}

ND: not determined

$\mathrm{CI}$ : confidence interval

the stomach of test mice ${ }^{10}$. The urease-producing ability of $H$. pylori has been known to play a crucial role in infection and survival of the pathogen in the stomach. Therefore, inhibition of the urease activity has also been considered as an alternative strategy for the treatment of the H. pylori infection. Hot water extracts, ether and EtOAc fractions of some mushrooms, such as Ganoderma lucidum, Coriolus versicolor, A garicus bisporus and Gyrophora esculenta, were reported to possess growth inhibitory activity against $H$. pylori, but these extracts and fractions showed no inhibitory effect on $H$. pylori urease activity $^{28}$. Several studies have reported on the inhibitory effect of plant preparations and phytochem- icals on $H$. pylori urease ${ }^{19,22,29}$. However, no information was reported on the inhibitory activity of $H$. erinaceus preparations or its constituents against urease activity of $H$. pylori. In our present study, the EtOAc fractions from both mycelium and culture filtrate of $H$. erinaceus exhibited growth inhibitory activity against $H$. pylori. They had a stronger inhibitory urease than the water fractions, while the polysaccharide and hexane fractions showed no effect.

$\mathrm{MeOH}$ extracts from fresh fruiting body and mycelium of $H$. erinaceus were found to have antioxidant activity in DPPH free radical scavenging, and the activity was not due to phenolic compounds in H. erinaceus extracts ${ }^{11}$. It was reported that polysac- 


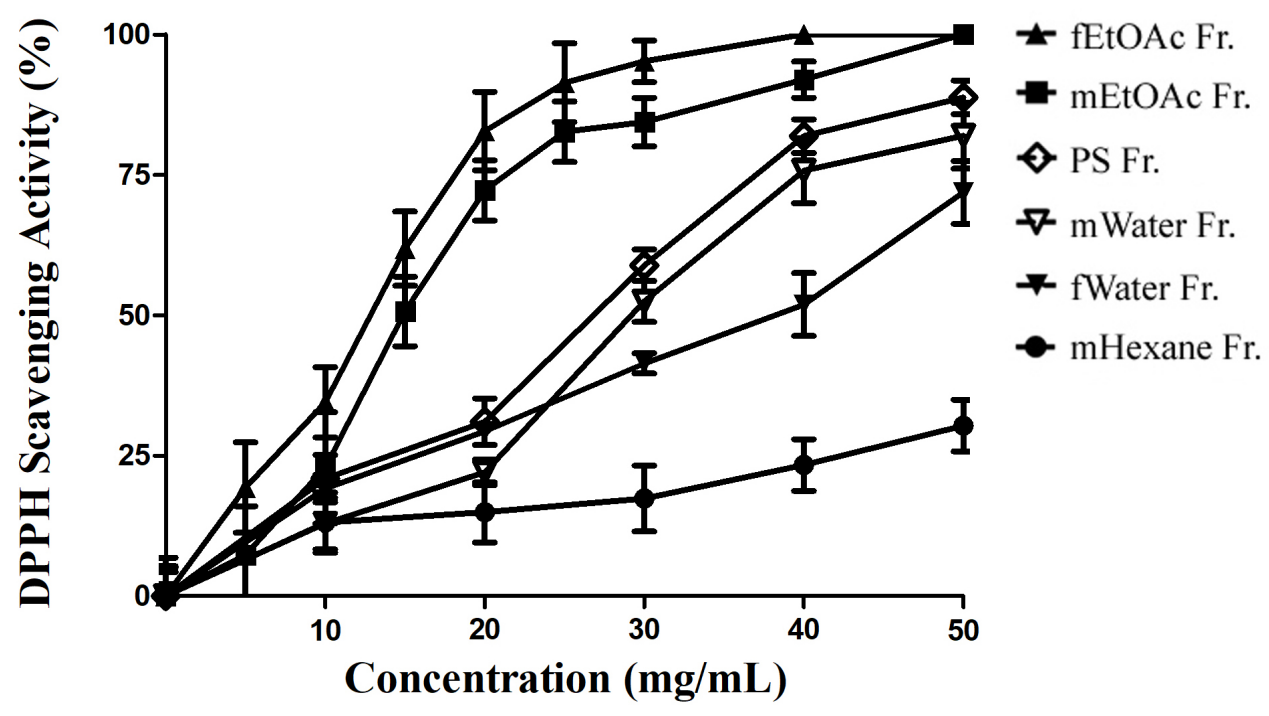

Figure 4: DPPH free radical scavenging activity of $H$. erinaceus mycelium and culture filtrate fractions toward H. pylori ATCC 43504.

charides purified from liquid culture of $H$. erinaceus mycelium enhanced the growth of rat adrenal nerve cells and improved the extension of neurites of PC12 cells ${ }^{30}$. The polysaccharide fraction from $H$. erinaceus mycelium was found to possess anti-ulcer and anti-gastritis activities ${ }^{31,32}$. Moreover, the antioxidant capacity of the polysaccharide fraction from $H$. erinaceus mycelium was higher than that of hot water extract from $H$. erinaceus fruiting body ${ }^{18}$. In our present study, the polysaccharide fraction from the culture filtrate of $H$. erinaceus showed a lower antioxidant effect than the EtOAc fractions from both the mycelium and culture filtrate. These results indicate that the EtOAC fractions from the mycelium and culture filtrate of $H$. erinaceus could exert growth-inhibiting and urease inhibitory effects on $H$. pylori to enhance antioxidant defense and protect the human stomach from $H$. pylori infection. More research is needed to prove the safety of the $H$. erinaceus mycelium and culture filtrate fractions and their in vivo efficacies in the treatment of $H$. pylori infection.

\section{CONCLUSION}

The present study revealed that the EtOAC fractions derived from the mycelium and culture filtrate of $H$. erinaceus exhibited pronounced antioxidant and inhibitory effects against $H$. pylori. The results suggest that the in vitro culture of mycelium and culture filtrate of $H$. erinaceus could be further studied to de- velop potent antibacterial products for the treatment of $H$. pylori infection.

\section{ABBREVIATIONS}

ATCC: American Type Culture Collection

CFU: Colony forming units

MIC: Minimal inhibitory concentration

MBC: Minimal bactericidal concentration

mHexane Fr.: Hexane fraction derived from mycelium

mEtOAc Fr:: Ethyl acetate fraction derived from mycelium

mWater Fr.: Water fraction derived from mycelium NBS: newborn bovine serum

PS Fr.: Polysachaccride fraction derived from culture filtrate

fHexane Fr.: Hexane fraction derived from culture filtrate

fEtOAc Fr.: Ethyl acetate fraction derived from culture filtrate

fEtOAc Fr.: Water fraction derived from culture filtrate

\section{ACKNOWLEDGMENTS}

All authors gratefully acknowledge the financial support from Vietnam National Foundation for Science and Technology Development (NAFOSTED) under grant number 106-YS.06-2015.17. 


\section{AUTHORS' CONTRIBUTIONS}

LTM Ngan, TT Hieu and PT Ho conceived and designed the experiments. LTM Ngan, TT Hieu, NT Vi, DTM Tham and LTT Loan performed the experiments. LTM Ngan, TT Hieu and NT Vi analyzed and interpreted the data. LTM Ngan and TT Hieu participated in drafting and writing the article. All authors read and approved the manuscript.

\section{FUNDING}

Vietnam National Foundation for Science and Technology Development (NAFOSTED) under grant number 106-YS.06-2015.17.

\section{AVAILABILITY OF DATA AND MATERIALS}

Data and materials used and/or analysed during the current study are available from the corresponding author on reasonable request.

\section{ETHICS APPROVAL AND CONSENT TO PARTICIPATE}

Not applicable.

\section{CONSENT FOR PUBLICATION}

Not applicable.

\section{COMPETING INTERESTS}

The authors declare that they have no competing interests.

\section{REFERENCES}

1. Hetland G, Tangen JM, Mahmood F, Mirlashari MR, NissenMeyer LSH, Nentwich I, Therkelsen SP, Tjønnfjord GE, Johnson E. Antitumor, anti-inflammatory and antiallergic effects of Agaricus blazei mushroom extract and the related medicinal Basidiomycetes mushrooms, Hericium erinaceus and Grifola frondosa: A review of preclinical and clinical studies. Nutrients. 2020;12(5):1339;PMID: 32397163. Available from: https: //doi.org/10.3390/nu12051339.

2. Lee EW, Shizuki K, Hosokawa S, Suzuki M, Suganuma H, Inakuma T, Li J, Ohnishi-Kameyama M, Nagata T, Furukawa $\mathrm{S}$, Kawagish $\mathrm{H}$. Two novel diterpenoids, erinacines $\mathrm{H}$ and I from the mycelia of Hericium erinaceum. Biosci Biotechnol Biochem. 2000;64(11):2402-2405;PMID: 11193408. Available from: https://doi.org/10.1271/bbb.64.2402.

3. Kenmoku H, Shimai T, Toyomasu T, Kato N, Sassa T. Erinacine $Q$, a new erinacine from Hericium erinaceum, and its biosynthetic route to erinacine $C$ in the basidiomycete. Biosci Biotechnol Biochem. 2002;66(3):571-575;PMID: 12005051. Available from: https://doi.org/10.1271/bbb.66.571.

4. Ashour A, Amen Y, Allam AE, Kudo T, Nagata M, Ohnuki K, Shimizu K. New isoindolinones from the fruiting bodies of the fungus Hericium erinaceus. Phytochem Lett. 2019;32:1014;Available from: https://doi.org/10.1016/j.phytol.2019.04. 017.

5. Mori K, Obara $Y$, Hirota $M$, Azumi $Y$, Kinugasa $S$, Inatomi $S$, Nakahata N. Nerve growth factor-inducing activity of Hericium erinaceus in 1321N1 human astrocytoma cells. Biol
Pharm Bull. 2008;31(9):1727-1732;PMID: 18758067. Available from: https://doi.org/10.1248/bpb.31.1727.

6. Kim SP, Kang MY, Kim JH, Nam SH, Friedman M. Composition and mechanism of antitumor effects of Hericium erinaceus mushroom extracts in tumor-bearing mice. J Agric Food Chem. 2011;59(18):9861-9869;PMID: 21846141. Available from: https://doi.org/10.1021/jf201944n.

7. Diling $C$, Xin Y, Chaoqun Z, Jian Y, Xiaocui T, Jun C, Ou S, Yizhen $X$. Extracts from Hericium erinaceus relieve inflammatory bowel disease by regulating immunity and gut microbiota. Oncotarget. 2017;8(49):85838-85857;PMID: 29156761. Available from: https://doi.org/10.18632/oncotarget.20689.

8. Xu H, Wu PR, Shen ZY, Chen XD. Chemical analysis of Hericium erinaceum polysaccharides and effect of the polysaccharides on derma antioxidant enzymes, MMP-1 and TIMP-1 activities. Int J Biol Macromol. 2010;47(1):33-36;PMID: 20380848. Available from: https://doi.org/10.1016/j.ijbiomac.2010.03.024.

9. Liu JH, Li L, Shang XD, Zhang JL, Tan Q. Anti-Helicobacter pylori activity of bioactive components isolated from Hericium erinaceus. J Ethnopharmacol. 2016;183:54-58;PMID: 26364939. Available from: https://doi.org/10.1016/j.jep.2015. 09.004 .

10. Wang G, Zhang X, Maier SE, Zhang L, Maier RJ. In vitro and in vivo inhibition of Helicobacter pylori by ethanolic extracts of lion's mane medicinal mushroom, Hericium erinaceus (Agaricomycetes). Int J Med Mushrooms. 2019;21(1):111;PMID: 30806251. Available from: https://doi.org/10.1615/ IntJMedMushrooms.2018029487.

11. Wong KH, Sabaratnam V, Abdullah N, Kuppusamy UR, Naidu M. Effects of cultivation techniques and processing on antimicrobial and antioxidant activities of Hericium erinaceus (Bull.: Fr.) Pers. extracts. Food Technol Biotechnol. 2009;47(1):4755;Available from: https://www.ftb.com.hr/images/pdfarticles/ 2009/January-March/47-47.pdf.

12. Kim SP, Moon E, Nam SH, Friedman M. Hericium erinaceus mushroom extracts protect infected mice against Salmonella Typhimurium-Induced liver damage and mortality by stimulation of innate immune cells. J Agric Food Chem. 2012;60(22):5590-5596;PMID: 22624604. Available from: https://doi.org/10.1021/jf300897w.

13. Shang $X$, Tan $Q$, Liu R, Yu K, Li P, Zhao GP. In vitro antiHelicobacter pylori effects of medicinal mushroom extracts, with special emphasis on the Lion's Mane mushroom, Hericium erinaceus (higher Basidiomycetes). Int J Med Mushrooms. 2013;15(2):163-174;PMID: 23557368. Available from: https://doi.org/10.1615/IntJMedMushr.v15.i2.50.

14. Atherton JC, Blaser MJ. Coadaptation of Helicobacter pylori and humans: ancient history, modern implications. J Clin Invest. 2009;119(9):2475-2487;PMID: 19729845. Available from: https://doi.org/10.1172/JCI38605.

15. Negrei C, Boda D. The Mechanisms of action and resistance to fluoroquinolone in Helicobacter pylori Infection. In: Roesler. Trends in Helicobacter pylori Infection BM editor. IntechOpen. 2014;349;Available from: https://doi.org/10.5772/57081.

16. Lee JS, Hong EK. Hericium erinaceus enhances doxorubicininduced apoptosis in human hepatocellular carcinoma cells. Cancer Lett. 2010;297(2):144-154;PMID: 20554107. Available from: https://doi.org/10.1016/j.canlet.2010.05.006.

17. Kuo HC, Lu CC, Shen CH, Tung SY, Hsieh MC, Lee KC, Lee LY, Chen CC, Teng CC, Huang WS, Chen TC. Hericium erinaceus mycelium and its isolated erinacine A protection from MPTPinduced neurotoxicity through the ER stress, triggering an apoptosis cascade. J Transl Med. 2016;14:78;PMID: 26988860. Available from: https://doi.org/10.1186/s12967-016-0831-y.

18. Wang $M$, Kanako N, Zhang $Y$, Xiao X, Gao Q, Tetsuya K. A unique polysaccharide purified from Hericium erinaceus mycelium prevents oxidative stress induced by $\mathrm{H} 2 \mathrm{O} 2$ in human gastric mucosa epithelium cell. PLoS ONE. 2017;12(7): e0181546;PMID: 28742114. Available from: https://doi.org/10. 1371/journal.pone.0181546. 
19. Ngan LTM, Moon JK, Shibamoto T, Ahn YJ. Growth-inhibiting, bactericidal, and urease inhibitory effects of Paeonia lactiflora root constituents and related compounds on antibioticsusceptible and -resistant strains of Helicobacter pylori. J Agric Food Chem. 2012;60(36):9062-9073;PMID: 22891951. Available from: https://doi.org/10.1021/jf3035034.

20. Ngan LTM. Antibacterial activity of ethanolic extracts of some Vietnamese medicinal plants against Helicobacter pylori. AIP Conference Proceedings. 2017; 1878(1):020030;Available from: https://doi.org/10.1063/1.5000198.

21. Icatlo FC, Jr Kuroki M, Kobayashi C, Yokoyama H, Ikemori Y, Hashi T, Kodama Y. Affinity purification of Helicobacter pylori urease. Relevance to gastric mucin adherence by urease protein. J Biol Chem. 1998;273(29):18130-18138;PMID: 9660771. Available from: https://doi.org/10.1074/jbc.273.29.18130.

22. Tran $\mathrm{TH}$, Truong $\mathrm{THH}$, Nguyen TTL, Nguyen $\mathrm{VMH}$, Nguyen TMN, Luong TMN. Growth-inhibiting, bactericidal, antibiofilm, and urease inhibitory activities of Hibiscus rosa sinensis $L$. flower constituents toward antibiotic sensitive- and resistantstrains of Helicobacter pylori. ACS Omega. 2020;5(32):2008020089;PMID: 32832762. Available from: https://doi.org/10. 1021/acsomega.0c01640.

23. Al-Sayed E, El-Naga RN. Protective role of ellagitannins from Eucalyptus citriodora against ethanol-induced gastric ulcer in rats: Impact on oxidative stress, inflammation and calcitoningene related peptide. Phytomed Int J Phytother Phytopharmacol. 2015;22(1):5-15;PMID: 25836864. Available from: https: //doi.org/10.1016/j.phymed.2014.10.002.

24. Wang M, Gao Y, Xu D, Konishi T, Gao Q. Hericium erinaceus (Yamabushitake): a unique resource for developing functional foods and medicines. Food Funct. 2014;5(12):30553064;PMID: 25317734. Available from: https://doi.org/10. 1039/C4FO00511B.

25. Kim KH, Noh HJ, Choi SU, Lee KR. Isohericenone, a new cytotoxic isoindolinone alkaloid from Hericium erinaceum. J Antibiot. 2012;65(11):575-577;PMID: 22828965. Available from: https://doi.org/10.1038/ja.2012.65.

26. Zhang CC, Yin X, Cao CY, Wei J, Zhang Q, Gao JM. Chemical constituents from Hericium erinaceus and their abil- ity to stimulate NGF-mediated neurite outgrowth on PC12 cells. Bioorg Med Chem Let. 2015;25(22):5078-5082;PMID 26481911. Available from: https://doi.org/10.1016/j.bmcl. 2015.10.016.

27. Trovato $A$, Siracusa $R$, Di Paola $R$, Scuto $M$, Ontario $M L$, Bua O, Di Mauro P, Toscano MA, Petralia CC, Maiolino L, Serra A. Redox modulation of cellular stress response and lipoxin A4 expression by Hericium erinaceus in rat brain: relevance to Alzheimer's disease pathogenesis. Immun Ageing 2016;13:23;PMID: 27398086. Available from: https://doi.org/ 10.1186/s12979-016-0078-8.

28. Kim DH, Bae EA, Jang IS, Han MJ. Anti-Helicobacter pylori activity of mushrooms. Arch Pharm Res. 1996;19:447449;Available from: https://doi.org/10.1007/BF02986009.

29. Lee HK, Song HE, Lee HB, Kim CS, Koketsu M, Ngan LTM, Ahn YJ. Growth inhibitory, bactericidal, and morphostructural effects of dehydrocostus lactone from Magnolia sieboldii leaves on antibiotic-susceptible and-resistant strains of Helicobacter pylori. PLoS One. 2014;9(4):e95530;PMID: 24747984. Available from: https://doi.org/10.1371/journal.pone.0095530.

30. Park YS, Lee HS, Won MH, Lee JH, Lee SY, Lee HY. Effect of an exo-polysaccharide from the culture broth of Hericium erinaceus on enhancement of growth and differentiation of rat adrenal nerve cells. Cytotechnology. 2002;39(3):155 162;PMID: 19003308. Available from: https://doi.org/10.1023/ A:1023963509393.

31. Wang $M$, Yang G, Xu D, Gao Q. A polysaccharide from cultured mycelium of Hericium erinaceus and its anti-chronic atrophic gastritis activity. Int J Biol Macromol. 2015;81:656-661;PMID 26314904. Available from: https://doi.org/10.1016/j.ijbiomac. 2015.08.043.

32. Wang M, Konishi T, Gao Y, Xu D, Gao Q. Anti-gastric ulcer activity of polysaccharide fraction isolated from mycelium culture of lion's mane medicinal mushroom, Hericium erinaceus (Higher Basidiomycetes). Int J Med Mushrooms. 2015;17(11):1055-1060;PMID: 26853960. Available from: https://doi.org/10.1615/IntJMedMushrooms.v17.i11.50. 